\title{
Metaforologia entre História dos Conceitos e Não- Conceitualidade: uma recepção intempestiva de Hans Blumenberg
}

\author{
Metaphorology between History of Concepts and Non-Conceptuality: \\ an untimely reception of Hans Blumenberg
}

Luiz Filipe Araújo Alves

luiz-filipe@ufv.br

(Universidade Federal de Viçosa, Minas Gerais, Brasil)

\begin{abstract}
Resumo: 0 presente artigo discute as transições que ocorreram quanto à metaforologia no pensamento de Hans Blumenberg (1920-1996), especialmente demarcando as possibilidades de sua recepção no Brasil. A metaforologia enquanto um dos projetos filosóficos de Blumenberg foi gestada nas discussões que envolveram a história dos conceitos nos anos de 1950 e sofreu significativas alterações a partir da década de 1970, em particular através dos influxos cada vez maiores da fenomenologia. Tais discussões levaram a uma revisão da própria metaforologia a partir de uma teoria da nãoconceitualidade, a qual - quanto aos seus fins - não estaria em sintonia com uma história dos conceitos.
\end{abstract}

Palavras-chave: Hans Blumenberg; Keywords: Hans Blumenberg; metaphorology;

metaforologia; história dos conceitos; não- history of concepts; non-conceptuality.

\begin{abstract}
The present paper outlines the transitions that occurred in the metaphorology of Hans Blumenberg's (19201996), especially emphasizing the possibilities of its reception in Brazil. Metaphorology as one of Blumenberg's philosophical projects was conceived in the discussions that involved the history of concepts in the 1950s and has experienced significant changes since the 1970s, particularly through the increasing influxes of phenomenology. These discussions led to a reexamination of metaphorology itself based on a theory of non-conceptuality, which as to its aims would not be in harmony with a history of concepts.
\end{abstract}

DOI: http://dx.doi.org/10.11606/issn.2318-9800.v25i4p13-30

\section{Introdução}

Hans Blumenberg (1920-1996) é um filósofo já consagrado nos círculos mais especializados dentro da academia há décadas. Entretanto, seu impacto se faz sentir recentemente pela intensa pesquisa nas universidades e institutos, bem como a publicação de uma série de textos póstumos a partir de 1997, intensificados pela proximidade do jubileu de 100 anos de nascimento do filósofo. ${ }^{1}$ Foi a metaforologia

1 Outro marco importante foi a criação em 2019 de uma associação internacional dedicada aos estudos que dialogam com seu pensamento, a Blumenberg-Gesellschaft, que tem como missão divulgar a obra, organizar eventos acadêmicos internacionais e interdisciplinares, assim como auxiliar na edição de fragmentos póstumos do autor. 
a reflexão de Hans Blumenberg que o projetou para círculos mais amplos de interesse filosófico e literário, mesmo que inicialmente restrita a círculos bastante especializados. Pode-se dizer preliminarmente que a metaforologia surge como uma reflexão sobre a função metafórica da linguagem explorando a fundo as suas dimensões históricas, filosóficas, literárias e culturais; e inicialmente inserida no desenvolvimento de uma História dos Conceitos no pós-guerra alemão da República de Bonn. Contudo, a partir dos escritos posteriores, Blumenberg inseriu a metáfora e a metaforologia no campo de sentido do Mundo da Vida [Lebenswelt] da tradição fenomenológica. Mesmo que não tenha existido nenhuma pretensão explícita por parte de Blumenberg em aderir a projetos ou programas filosóficos, alguns autores inserem o seu pensamento como um dos marcos contemporâneos da Filosofia da Cultura [Kulturphilosophie] que se desenvolve especialmente na tradição alemã (Konersmann, 2012, p. 181-184).

Entretanto, a metaforologia é apenas um dos projetos que se desdobram a partir da extensa obra de Blumenberg, mas que de modo algum a ela se limita. ${ }^{2}$ Pelo contrário, trata-se de um filósofo que certamente não se insere na tradição sistemática da filosofia e que não elegeu a metaforologia como sua disciplina estética (Blumenberg, 2007, p. 28). Na realidade a metáfora é um meio estético que revela a esfera de origem do conceito e aponta para outras dimensões da filosofia. Uma estética eminentemente metaforológica seria uma dimensão, que mesmo passível de ser utilizada, explicitamente marcaria uma via não assumida pelo autor, mesmo que isso pouco valha num paradigma barthesiano.

Inegavelmente, Hans Blumenberg é um pensador extremamente erudito, metódico e irônico ${ }^{3}$ que elaborou e aprofundou diversas dimensões da filosofia contemporânea. Numa breve analogia, estaria Blumenberg mais próximo da Gaia Ciência nietzschiana do que do Espírito Absoluto hegeliano. E, assim como em Nietzsche, temos em Blumenberg uma filosofia que se revela em vários projetos internos e aprofundamentos ao longo dos anos. A própria metaforologia passou por transformações significativas ao longo de sua trajetória intelectual. Ainda numa aproximação com Nietzsche, o papel de Paradigmas para uma Metaforologia é

2 A publicação recorrente de textos póstumos de Blumenberg desde sua morte fortalece a pluralidade de caminhos e traços filosóficos de sua obra, especialmente quanto a suas pretensões de uma "fenomenologia da história" anunciada em 1981 na introdução de "Realidades em que vivemos" (Blumenberg, 2012b, p. 6), que foi colocada em movimento não apenas com essa coletânea de artigos, mas também com sua última obra publicada em vida, "Saídas da Caverna", que pode ser lida como parte de sua antropologia fenomenológica, também esboçada já em "Aproximação antropológica à atualidade da retórica" (idem, p. 107; 2018), um texto originalmente publicado em 1971, um ano que como veremos marca uma mudança da próprio Blumenberg quanto à História dos Conceitos.

3 Nisto o recente documentário Hans Blumenberg: O Filósofo Invisível [Der unsichtbare Philosoph], traz elementos extremamente interessantes que iluminam a filosofia de Blumenberg. Exibido em pré-estreia no primeiro congresso internacional da Blumenberg-Gesellschaft em 10 a 12 de outubro de 2019. Cf. Rüter, 2020. 
semelhante ao de Nascimento da Tragédia, pois são obras que lançam os filósofos num debate intelectual com fortes reações positivas e negativas, mas que também influenciam o modo de recepção. Ou seja, ao se partir unilateralmente de uma destas obras - sem atenção aos desenvolvimentos posteriores - tender-se-ia a uma leitura demasiadamente estética dos mesmos; e aqui também não se deve levar a parte pelo todo.

Por outro lado, a recepção de um autor de língua alemã, quando sua obra é produzida apenas neste idioma, perpassa necessariamente traduções para a divulgação num espectro mais amplo. Nas tradições de língua inglesa, francesa, espanhola e italiana as traduções da obra do filósofo se iniciaram ainda em vida a partir da década de 80. Em língua portuguesa temos apenas as traduções de duas obras (Blumenberg, 1990, 2013a) e poucos artigos (por exemplo, Blumenberg, 2010a, 2018), e mesmo a literatura secundária é parca, ${ }^{4}$ o que demonstra entre nós a incipiência dos estudos blumenberguianos. No Brasil, a primeira onda da recepção de Hans Blumenberg se deve principalmente a dois pesquisadores: Luiz Costa Lima ${ }^{5}$ e João Maurício Adeodato. ${ }^{6}$ Ambos com imensas inovações em seus campos de conhecimento e vínculos com a tradição germânica, o primeiro da teoria da literatura, o segundo da teoria e filosofia do direito.

Devido a esses fatos, a apresentação de alguns contextos intelectuais será necessária para se compreender elementos que fizeram parte do desenvolvimento do pensamento de Hans Blumenberg naquilo que é pertinente para este trabalho. Todavia, por ser um autor relativamente novo para a tradição filosófica, a sua recepção pode receber algumas perturbações ou dificuldades por ainda não se ter uma representação completa de seu pensamento. Deste modo, a meta do presente trabalho é bastante modesta: compreender a metaforologia dentro do seu contexto intelectual de formação para que sua recepção se dê de forma historicizada até a publicação de Paradigmas para uma Metaforologia em 1960 e o movimento inicial de afastamento da História do Conceitos.

Assim, num primeiro momento, será apresentado o posicionamento da metaforologia dentro da obra de Hans Blumenberg, demonstrando seus desenvolvimentos e seus problemas. Adotaremos esse modo de trabalho para contribuir com a recepção da obra de Hans Blumenberg no Brasil, para que não ocorram certas simplificações ou mesmo anacronismos em relação à metaforologia,

4 Importante é o papel de Olivier Feron que atua na Universidade de Évora e atuou como professor visitante no Brasil, auxiliando a revista Aurora da PUC-PR a publicar um dossiê especial dedicado a Hans Blumenberg. (Feron, 2015).

5 Pesquisador que já na década de 1980 promove a recepção de Hans Blumenberg no Brasil. Cf. Lima, 1980, p. 49, 57. Especialmente: Lima, 2015.

6 De modo completamente inovador traz Hans Blumenberg para a Filosofia do Direito brasileira. Cf. Adeodato, 1996, p. 197, 200 e Adeodato, 2014, p. 114, 140, 187, 316. 
considerando o status dos estudos blumenberguianos em âmbito internacional. Num segundo momento, serão apresentados e reconstruídos brevemente os contextos intelectuais onde foram gestadas as discussões entre conceitualidade e não-conceitualidade, com especial destaque para as relações de Hans Blumenberg com a história dos conceitos. Por fim, será discutida se é possível uma releitura da metaforologia a partir da filosofia tardia de Blumenberg ou se necessariamente este projeto está vinculado e limitado à história dos conceitos. Concluindo-se que tanto a metaforologia quanto seu esboço de desenvolvimento através de uma teoria da nãoconceitualidade são modelos interessantes ao deslocarem a linguagem e o discurso do eixo de um racionalismo exacerbado, contudo sem ser o programa final da reflexão blumenberguiana, e devem ser referenciados com prudência na recepção, ainda em progresso, da obra do filósofo.

\section{A Metaforologia em Hans Blumenberg}

Apesar de todo um campo de estudos no século XX voltado para uma série de teorias da metáfora, seja na linguística ou na teoria da literatura, ${ }^{7}$ Hans Blumenberg não deixou nem uma teoria da metáfora, nem uma metodologia da pesquisa da metáfora stricto sensu. Conforme esclarece Petra Gehring (2014, p. 201), o que temos nos primeiros escritos metaforológicos de Blumenberg seria muito mais um modo de trabalho para a metáfora enquanto problema filosófico que se desenvolveria inicialmente como um campo complementar à história dos conceitos, ou seja, enquanto potencial para uma história das metáforas. Em dado momento, os dois projetos possuem inter-relações; todavia, isso não significa que a metaforologia esteja subordinada necessariamente a uma história dos conceitos. Neste sentido, dentro de um exercício teórico quanto ao caminho que levaria à gênese da metaforologia no pensamento de Blumenberg, compreende-se aqui a pertinência deste retorno para que não ocorram enganos quanto a soluções simplistas e reducionistas, e este é principal intuito deste trabalho, a da mera subordinação da metaforologia à história dos conceitos, que por sua vez pode levar a interpretações limitadoras e até equivocadas sobre a própria reflexão posterior do filósofo.

Dito isto, podemos considerar Paradigmas para uma Metaforologia um texto de transição intelectual de Blumenberg, gestado após sua habilitação para docência e

\footnotetext{
7 Para uma antologia dos principais textos das teorias das metáforas no século XX na tradição alemã, especialmente quanto ao papel de Hans Blumenberg, cf. Haverkamp (1996), coletânea inicialmente publicada em 1983 e que até 1998 foi a principal fonte para o acesso ao texto, mesmo que parcial, de Paradigmas para uma metaforologia, já que o texto originalmente publicado no Archiv für Begriffsgeschichte em 1960 não era propriamente uma publicação autônoma e nunca foi revisado em vida por Blumenberg para uma publicação, apesar da insistência da própria Suhrkamp. Sobre essa reconstrução cf. Zill in Blumenberg, 2019, p. 187 e segs. A mencionada coletânea destaca em grande medida o papel de Blumenberg, tanto que conclui a seleção com os esboços do filósofo para uma possível revisão da Metaforologia por meio da Teoria da Não-conceitualidade.
} 
durante o chamado para suas primeiras cátedras. Ao contrário do que pareceria óbvio, a metaforologia não nasce com a publicação dos Paradigmas em 1960 no Arquivo para História dos Conceitos [Archiv für Begriffsgeschichte]. Tal texto é apenas a emanação de reflexões anteriores. Os estudiosos da obra de Hans Blumenberg traçam gêneses para a metaforologia que vão muito além do texto publicado. Assim, faremos o percurso em ordem inversa, como ao se explorar a fonte de um rio, para demonstrar que o problema é mais complexo do que parece à primeira vista e acima de tudo para evidenciar desde já quão problemática pode ser uma suposta subserviência da metaforologia para com a história dos conceitos.

Neste iter às avessas, a primeira paragem anterior seria o texto da conferência "Paradigmas para uma Metaforologia", com o protocolo das discussões, intitulado “Teses para uma Metaforologia”, que fora apresentado em 1958 junto à Comissão Senatorial para História dos Conceitos da Comunidade de Pesquisa Alemã (DFG), republicado em 2011 num estudo histórico de Margarita Kranz (2011, p. 186-193) sobre o contexto institucional da história dos conceitos que esclarece detalhes importantes sobre a questão. Tais teses, por sua vez, desenvolviam uma nova reflexão em relação a um texto anterior de 1957 Luz como Metáfora da Verdade: em um campo preliminar para a formação filosófica dos conceitos (Blumenberg, 2001, p. 139-171). Estes dois textos por si só possuem caráter renovador para a compreensão da metáfora como problema filosófico no século XX, superando em muito a estreita visão das figuras de pensamento como mero catálogo de tropos, sendo muitas vezes apenas este último referenciado como a origem da metaforologia na obra de Hans Blumenberg.

Outro momento da gênese da metaforologia aparece em um texto discutido em 1952 perante colegas na Universidade de Kiel denominado Técnica e Verdade e apresentado enquanto conferência em 1953 no $11^{\circ}$ congresso internacional de filosofia em Bruxelas. ${ }^{8}$ Neste texto, Hans Blumenberg já no primeiro parágrafo dita a tônica do trabalho e deixa entrever questões que retornarão posteriormente em obra: ${ }^{9}$

$\mathrm{Na}$ antiguidade o ente natural tem uma prevalência ontológica sobre o fabricado. A Physis é essencialmente "por si mesma", e ela é essencialmente "por si mesma" verdadeira. Tão verdadeira quanto é a natureza, tão "natural" quanto é a verdade. A maneira como isso se expressa se serve da metáfora da luz. Sob a luz se articula o ente enquanto Kosmos, a ordem regulativa e razoável. Verdade é então aquilo que “ilumina” (Blumenberg, 2015, p. 42, itálicos e aspas no original).

Inicialmente o trecho citado não traz nada de novo, chega até ser óbvio se consideramos a constituição da ontologia do mundo antigo e a perene tensão entre Physis e Nomos. Entretanto, o modo de colocação do problema e a escolha

8 Conforme nos informa um dos organizadores da obra póstuma de Blumenberg. Cf. Zill in Blumenberg, 2019, p. 185-186.

9 Todas as traduções do alemão são nossas, caso contrário informaremos o tradutor. 
cuidadosa das palavras em sua abertura já apresentam discussões que eram caras a Blumenberg como, por exemplo, o substrato metafórico que reside na ontologia ocidental. Kosmos e Logos enquanto a própria relação com e no mundo reaparecem em vários momentos da obra do filósofo. ${ }^{10}$ Ademais, o modo de problematização do ente [Seiende] e da ontologia remetem necessariamente às marcas das influências que Edmund Husserl e Martin Heidegger (mesmo que quanto a este último com muitas divergências) deixaram na obra blumenberguiana. ${ }^{11}$

Não é vão o privilégio que o jovem Blumenberg dá à metafórica da luz, por exemplo, em contraposição a metáfora da verdade como esquecimento [Alétheia], como na leitura heideggeriana para uma história do ser. ${ }^{12}$ Um problema na recepção de Blumenberg é que ele se apresenta como um mestre dos desvios [Umwege] e, por isso, nunca se contrapõe diretamente aos autores da tradição alemã, já que de outras tradições sistematicamente ignora, mesmo contemporâneos como Foucault, Ricoeur e Derrida. Todavia, este não é o caso com Heidegger, Gehlen e Schmitt. Em relação a eles existem leituras atentas e críticas veladas e desveladas por parte de Blumenberg. ${ }^{13}$ Pode-se perceber desde já que se tratam de matrizes de pensamento significativamente distantes das tradições que orientaram a história dos conceitos, especialmente no Brasil onde a recepção da história dos conceitos está demasiadamente centralizada na figura de Reinhart Koselleck. ${ }^{14}$

Todavia, as discussões sobre a metafórica da linguagem não se iniciam neste texto de 1952, sendo este também um subproduto da própria tese de habilitação defendida em Kiel em 1950, período em que o autor teve lições com dois ex-assistentes

10 Elementos que perpassam a obra "A Legibilidade do Mundo", que seria parte de um projeto inconcluso para a reformulação da metaforologia.

11 Assim como Ernst Cassirer e Arnold Gehlen, que não estão presentes no trecho citado, mas que impactaram significativamente Hans Blumenberg quanto ao modo de pensar e superar esses próprios autores.

12 Para Blumenberg: “A lendária segunda parte de 'Ser e Tempo' nunca foi escrita porque não era possível escrevê-la" (Blumenberg, 1997, p. 159), pois o Ser é como o MacGuffin de Alfred Hitchcock. Em tom anedótico, Blumenberg compara o vazio de um aparato para caçar leões nas montanhas de Adirondacks, quando não existem leões nas montanhas de Adirondacks, com a pergunta pelo ser (idem, p. 157).

13 Por coincidência, todos com laços com obscuros com o nacional-socialismo, ou sem traços de remorso por tais vínculos no pós-guerra. Não é sem razão que Legitimidade da Idade Moderna (1966) desde sua primeira edição contém uma crítica ao conceito de secularização que atinge exatamente a tese da teologia política de Carl Schmitt, o que fica ainda mais claro a partir das cartas de Blumenberg com Carl Schmitt e com Jacob Taubes. Ou mesmo, o póstumo Descrição do Humano pode ler lido como certas respostas a Arnold Gehlen, mas acima de tudo como uma antropologia fenomenológica, que para os círculos husserlianos ou heideggerianos mais clássicos poderia ser uma construção vã. Quanto a afinidades com Husserl e a distância de Heidegger, o também póstumo “Ein mögliches Selbstverständnis" (Blumenberg, 1997, p. 139-176) explicita bastante essa controvérsia [Auseinandersetzung].

14 Uma História dos Conceitos e uma semântica histórica são muito mais amplas do que as contribuições de Koselleck, por mais importante que sejam. Para um panorama crítico destas e a presença de Blumenberg em momentos e posições distintas Cf. Müller; Schmieder, 2016, p. 149 e segs., 764 e segs. 
Metaforologia entre História dos Conceitos e Não-Conceitualidade: uma recepção ...

exatamente de duas grandes influências que marcam o seu itinerário filosófico: Ludwig Landgrebe, assistente de Husserl, e Walter Bröcker, assistente de Heidegger. Neste sentido, Philip Stoellger (2000), que defendeu uma das primeiras teses de doutorado dedicada ao pensamento de Hans Blumenberg, foi também o primeiro a destacar a gestação da metaforologia dentro da tese de habilitação $A$ distância ontológica: Uma investigação sobre a crise da fenomenologia de Husserl. Neste texto, ainda não publicado, Blumenberg também explora o problema da metafórica quando pretende introduzir a discussão quanto ao conceito de movimento ontológico [ontologischen Bewegungsbegriff] em relação ao conceito de declínio [Verfall]; assim expõe ${ }^{15}$ :

A metafórica espacial da versão deste fundamento [do Conceito de movimento] é assim pressuposta; pode-se dizer grosseiramente que a ontologia clássica como ontologia da essência da forma do existente [Seienden] tem em vista enquanto ontologia existencial da "motricidade" interior da existência humana, mas que o pensamento que une o Ser e a História se volta aqui para o "campo de ação" [Spielraum] e procura prever e determinar a sua "espacialidade" como uma dimensão da metacinética histórica (Blumenberg, 1950. p. 10).

Há uma reverberação direta deste texto com o desenvolvimento da metaforologia. 0 conceito de metacinética ${ }^{16}$ é um dos elementos centrais da metaforologia nos limites que ficaram expressos nos Paradigmas de 1960, mesmo que não tenha sido efetivamente introduzido nesta obra. Por sua vez, este termo retirado da filosofia aristotélica - Kinesis - foi recepcionado por Blumenberg através das lições de Walter Bröcker, que nas trilhas heideggerianas promoveu uma leitura fenomenológica da categoria do movimento na obra de Aristóteles. Essa transição é destacada por Anselm Haverkamp (2018, p. 47) enquanto uma chave de leitura essencial para compreensão da metaforologia tal qual foi concebida por Blumenberg na década de 50 do século passado. Porquanto, a dimensão da linguagem já estava presente para Hans Blumenberg desde suas primeiras publicações, como destaca Kurt Flasch (2017, p. 7) em obra dedicada ao pensamento de Blumenberg entre 1945 e 1966 com a publicação de $A$ Legitimidade da Idade Moderna.

Ainda neste retorno às fontes, em um texto de poucas páginas de 1946/1947, intitulado $A$ realidade linguística da filosofia, ${ }^{17}$ pretende Blumenberg explicar de

15 Conseguimos acesso à tese em período de pesquisa na Universidade de Kiel (2019/2020); por se tratar de material inédito faremos referência naquilo que for pertinente aos fins desse artigo como elemento de esclarecimento da trajetória de Hans Blumenberg.

16 A metacinética adentra na introdução dos Paradigmas sem apresentações quanto ao conceito (Blumenberg, 2013, p. 16); e aparece como modo de substituição do movimento da história do ser quanto a "essência" da verdade na era da técnica para compreender o conceito de verdade em sua função, ao invés de uma suposição quanto a sua substância. Cf. Anselm Haverkamp (2018, p. 48). Tais elementos vão redundar exatamente em uma substituição do exame de um conceito de verdade para os conceitos de realidades. Algo que já estava presente desde os textos iniciais do Hermeneutik und Poetik, mas agora com mais razão em Realidade e Realismo (Blumenberg, 2020a).

17 Blumenberg, 2020b, p. 33-39. Neste texto do jovem Blumenberg, considerado seu primeiro texto 
modo plausível para uma grande audiência a razão pela qual os filósofos utilizam uma linguagem técnica que geralmente é de difícil compreensão, e esta razão é para ele histórica, acima de tudo pelo peso da tradição e da tradução da linguagem. ${ }^{18}$ Kurt Flasch (2017, p. 369) retoma exatamente esse ponto de partida em Blumenberg como abertura da dimensão sobre como um filosofar através de metáforas, que posteriormente esteve presente na tese de habilitação e em outros textos da década de 1950 até alcançar a forma dos Paradigmas para uma Metaforologia de 1960. Neste sentido, Kurt Flasch fala sobre um filosofar com metáforas em Hans Blumenberg que não se centraliza na concepção da metaforologia como fim em si mesmo, mas apenas como um momento de reflexão mais profunda sobre o problema da historicidade que marca todo seu esforço filosófico.

Tanto Anselm Haverkamp quanto Kurt Flasch retomam a centralidade da tese de habilitação de Hans Blumenberg para a constituição da metaforologia. Por sua vez, Phillip Stoellger (2009, p. 204-206), ao propor uma discussão quanto ao terminus a quo da metaforologia, lança a hipótese de que uma datação primeva poderia se encontrar além da tese de habilitação, retornando até mesmo à tese de doutorado de Hans Blumenberg: Contribuições para o problema da originalidade da ontologia escolástica medieval de 1947. Neste momento, Blumenberg já elaborara elementos pré-predicativos e pré-conceituais que ecoariam até a sua ampliação da metaforologia para uma teoria da não-conceitualidade. Mais uma vez o caso exemplar é quanto à metáfora da luz, sendo para Blumenberg que a metáfora solar para a ideia de bem seria uma variante para a metáfora da luz para a verdade e o que faz com que essa metáfora tenha sua razão é que ela já é uma forma específica de compreensão de ser [Seinsverständnisses]. ${ }^{19}$

Esta breve regressão demonstra como a própria metaforologia fora explicitada ao menos desde 1958, ao invés da referência comum aos Paradigmas de 1960; bem como a dimensão da metafórica e da historicidade já estavam presentes em diversos trabalhos anteriores. 0 que nos leva a dizer que há uma dimensão da metaforologia antes e depois dos Paradigmas, pois a recepção do texto de forma autônoma e

filosófico publicado, há claramente a preocupação quanto aos conceitos filosóficos. Não só quanto aos problemas da tradução dos termos gregos para a linguagem filosófica latina (p. 36), porém também a suspeita quanto a uma depuração terminológica da própria filosofia enquanto ciência rigorosa aos olhos de Husserl (idem, p. 38). Quando ressoa a pergunta retórica que a metaforologia irá revelar uma (im)possibilidade: "Mas devemos nos perguntar: Existe uma metodologia rigorosa que nos permite consertar os elementos de intuição encontrados na linguagem?” (idem, p. 38)

18 Anselm Haverkamp também aponta este texto como um ponto de partida para as reflexões que vão culminar com os Paradigmas de 1960, que apresentam ao seu ver as garras de um leão que se deixou domesticar. Cf. Haverkamp, 2018, p. 31. Nota 7.

19 Anselm Haverkamp destaca o aspecto que tanto a tese de doutorado quanto a de habilitação de Blumenberg são esforços de contraposição a Heidegger (Haverkamp, 2018, p. 24). Para um estudo mais focado nas relações entre Blumenberg e Heidegger veja-se o texto "Blumenberg versus Heidegger: La metaforología como destino del análisis existencial” (González-Cantón, 2005, p. 725-746). 
Metaforologia entre História dos Conceitos e Não-Conceitualidade: uma recepção ...

cada vez mais inserida no contexto da história dos conceitos nos seus Arquivos e, como veremos, na preparação para o Dicionário Histórico de Filosofia [Historisches Wörterbuch der Philosophie - HWPh]. Toda esta complexa teia de discursos promoveu certos encurtamentos históricos da própria metaforologia, os quais pretendemos contribuir para o seu esclarecimento.

\section{A Metaforologia e a História dos Conceitos}

Neste item pretendemos perscrutar as relações da metaforologia com a história dos conceitos. De certo modo nosso intento é esclarecer duas posições que são tomadas como definidoras quanto ao pensamento - e até quanto à biografia - de Hans Blumenberg. A primeira opinião comumente repetida seria que a metaforologia serviria tão somente como um campo auxiliar ou complementar à história dos $\operatorname{conceitos}^{20}$ e a segunda seria que mesmo nesta posição acessória à história dos conceitos a metaforologia de Blumenberg teria sido excluída do Dicionário Histórico de Filosofia $[H W P h]^{21}$, que pode ser considerado um dos maiores, se não o maior, projeto de um dicionário histórico guiado por diretrizes que dialogam com a História dos Conceitos, mesmo que sem uma definição teórica pré-determinada, como veremos.

Iniciaremos pela segunda posição, que até muito recentemente foi aceita no Brasil, e a partir da qual era considerado que Blumenberg havia sido excluído por Joachim Ritter do projeto do dicionário (Lima in Blumenberg, 2013, p.14). ${ }^{22}$ Tal ilação talvez se deu pela manifestação de Ritter no prefácio do HWPh, quando o organizador justificou a questão metaforológica a partir da posição da comissão organizadora que:23

renunciou a aceitar metáforas e mudanças metafóricas na relação dos verbetes [Nomenklatur] do Dicionário, embora lhe fosse claro, como H. Blumenberg mostrara, que metáforas resistentes à desintegração na conceitualidade têm "uma história em um sentido mais radical que os conceitos" e conduzem à "subestrutura do

20 "Isso, porque a metaforologia consiste em uma espécie de complemento à história dos conceitos alemã, modulando um pouco seu otimismo racionalista" (Santos, 2020, p. 301). Assim como Oliveira, 2013, p. 114.

21 "Deve ter sido Rothacker quem o convidou a participar do grupo encarregado de pensar a elaboração do Dicionário, se não, mais precisamente, de desenvolver a presença de metáforas na história dos conceitos. A morte do fundador da Archiv e sua substituição por um erudito menos inovador, Joachim Ritter, são suficientes para explicar a recusa da proposta de Blumenberg." Lima in Blumenberg, 2013. p. 14. Assim como Oliveira, 2013, p. 114, sem ter contato com a leitura de Lima, 2013.

22 Posição que foi moderada em posteriormente (Lima, 2015, p. 166) e mais próxima dos fatos, pois não foi Blumenberg o excluído do dicionário, mas uma possível autonomia da metaforologia como projeto ou delineamento dentro do projeto. Para a mais fidedigna reconstrução desse contexto cf. Kranz, 2011; 2013.

23 Tradução de Lima in Blumenberg, 2013. p. 14-15. 
pensamento”, que é a “nutriz das cristalizações sistemáticas”. A razão dessa renúncia esteve na percepção de que, no estado atual das pesquisas neste campo, isso exigiria demasiado do Dicionário e que, em vez de nos contentarmos com uma improvisação insuficiente, é preferível deixar de lado um campo a que não se poderá fazer justiça (Ritter et al., 2007, v. 1, p. viii-ix).

Poder-se-ia pensar que, apesar de polida, a justificativa pareceria demonstrar a intenção deliberada de não contemplar e até mesmo excluir discussões metafóricas sobre os conceitos filosóficos, ou seja, a partir dos Paradigmas conforme proposto por Blumenberg. Assim, também poderia parecer, numa clara ilação, que Blumenberg tivesse sido, portanto, excluído do projeto do dicionário. Todavia, não parece que essa tenha sido a narrativa mais crível. Fato é que, mesmo antes da morte de Erich Rothacker em 1965, Joachim Ritter assumiu a codireção dos Arquivos de História dos Conceitos juntamente com Gadamer, e liderou um novo projeto de dicionário, o qual certamente acabou se afastando das linhas iniciais de Rothacker que poderiam contemplar estudos dentro do campo das metáforas e sua relação com os conceitos filosóficos. Entretanto, antes destas mudanças, para o projeto inicial foi organizada uma série de estudos preparatórios, e por iniciativa de Rothacker, já experiente estudioso das humanidades em seu caráter interdisciplinar, Hans Blumenberg foi convidado em 1958 e publicou em 1960 o texto Paradigmas para uma Metaforologia no Arquivo para História dos Conceitos, como visto no item anterior.

Guardando prudência quanto a este tema, devemos destacar que não há uma única história dos conceitos, mas histórias dos conceitos, isto é, projetos que competiram e concorreram por hegemonia no contexto filosófico alemão do pósguerra. Joachim Ritter e seu círculo de estudantes, comumente referenciado como Ritterschule, ${ }^{24}$ apesar de orientação neohegeliana, não possuía nenhuma ideologia unificadora ou maior homogeneidade como sua concorrente, a Escola de Frankfurt. Apesar disso, podemos ao menos distinguir três grandes correntes da história dos conceitos no contexto alemão: as incursões de Erich Rothacker desde seu esforço inicial junto à DFG, da Academia de Mainz a partir de 1949 e do e dos Arquivo a partir de 1955; um segundo projeto a partir de Joachim Ritter com o apoio de Gadamer que culminaria no HWPh a partir de 1964; e um projeto que hoje é referenciado a partir da figura de Reinhard Koselleck que resultou no Conceitos Históricos Fundamentais [Geschichtliche Grundbegriffe] a partir de 1967.

Quanto ao posicionamento de Blumenberg em relação à história dos conceitos, trata-se de um dos temas mais espinhosos na recepção do filósofo. A posição mais simples seria assumir a subsidiariedade e a dependência que a metaforologia teria para com a história dos conceitos. Na introdução de Paradigmas para uma Metaforologia, Blumenberg fala da tarefa de uma "paradigmática metaforológica"

24 Para uma reconstrução do contexto conservador-liberal alemão no pós-guerra cf. Hacke, 2006. 
para uma "investigação mais profunda ainda pendente" (Blumenberg, 2013b, p. 16), ou seja, o intento de um novo dicionário filosófico, já que as metáforas, e em especial as metáforas absolutas, "têm história num sentido mais radical do que os conceitos", pois a metáfora coloca em perspectiva a "metacinética dos horizontes históricos de sentido" e dos modos de visão em cujo interior os conceitos experimentam a sua modificação:

Através dessa relação de implicação determina-se a relação da metaforologia para com a história dos conceitos (em sentido estritamente terminológico) com tal disposição para serviço [Dienstbarkeit]: a metaforologia procura adentrar na subestrutura do pensamento, ao seu subsolo, na solução saturada das cristalizações sistemáticas (Blumenberg, 2013b, p. 16-17).

Esse trecho traz alguns elementos interessantes para esclarecer a relação da metaforologia com a história dos conceitos, em especial uma famigerada "subserviência" e subsidiariedade. Em primeiro lugar, devemos compreender que a palavra Dienstbarkeit no alemão é polissêmica, e não podemos excluir a possibilidade da ironia, traço peculiar na escrita de Hans Blumenberg. Em segundo lugar, Dienstbarkeit seria aquilo que está disponível para prestar um serviço, um trabalho, mas que pode também significar: solicitude, dependência, submissão, servidão. Por exemplo, Anselm Haverkamp, em seus comentários aos Paradigmas, aduz que a Dienstbarkeit aqui é uma metáfora irônica que evoca uma relação dialética como na dialética do senhor e do escravo em Hegel (Haverkamp in Blumenberg, 2013b, p. 274.). Neste contexto, o termo anterior que expõe o sentido desta disposição para serviço é "relação de implicação" entre a metaforologia e a história dos conceitos, pois implicação é uma função e não uma subordinação.

Todavia, essa exegese do texto pode não ser suficiente para esclarecer o que em 1960 significou esse serviço da metaforologia para com a história dos conceitos. Talvez o maior esclarecimento que necessita ser feito é sobre o que significava a História dos Conceitos entre 1955 e 1960; bem como, se existia algum programa metodológico para ela naquele momento. E é exatamente esta falta de contextualização que faz reforçar uma leitura anacrônica dos Paradigmas, texto que pelo caráter provisional só pode ser lido de forma menos prejudicial se compreendido à luz da obra posterior de Hans Blumenberg. No mencionado período, a História dos Conceitos está relacionada com as concepções e projetos sob a figura de Erich Rothacker, e por isso suficientemente anterior às construções e justificativas teóricas de Ritter (1967) e Koselleck (1967), ambas publicadas no mesmo volume dos Arquivos para História dos Conceitos; ou mesmo o elogio a posteriori feito por Gadamer (1970). Deste modo, Hans Blumenberg esteve vinculado à visão de história dos conceitos de Erich Rothacker, e foi ela que teve em mente quando da composição dos Paradigmas para uma Metaforologia em 1960. 
Após considerar todo esse contexto intelectual, Margarita Kranz escreveu um texto imprescindível - a partir de uma longa pesquisa institucional - para o preenchimento deste quebra-cabeça das relações entre metaforologia e história dos conceitos. O texto intitulado "História dos Conceitos de Blumenberg: do início ao fim de todos serviços" (Kranz, 2013) é certamente até o presente momento o texto mais verossímil sobre tais relações. Assumindo a sistematização de Margarita Kranz, podemos nos conduzir em três momentos das posições de Blumenberg sobre a história dos conceitos. Um primeiro momento afirmativo das intenções de Erich Rothacker e dos Arquivos de História dos Conceitos; um segundo momento quanto ao posicionamento pessoal de Blumenberg sobre o trabalho da história conceitual; e, por fim, seu movimento de espectador desinteressado do projeto do dicionário histórico de Ritter em meados da década de 1960 para observador crítico a partir de 1971 com a publicação do primeiro volume (Kranz, 2013, p. 232). Pode-se perceber pelo itinerário regressivo que fizemos sobre a metaforologia que as reflexões de Hans Blumenberg sobre a história e historicidade nascem de preocupações diversas e em momento anterior aos diálogos que o filósofo manteria com a história dos conceitos em seus momentos iniciais.

Por isso, podemos concordar que o modo de expressão de que a metaforologia esteve a serviço da história dos conceitos [im Dienst der Begriffsgeschichte] (Blumenberg, 1979, p. 86) deve ser considerado não apenas sistematicamente, mas também institucionalmente. Expressão que foi novamente utilizada por Blumenberg praticamente vinte anos depois dos Paradigmas para se referir no Panorama sobre uma teoria da não-conceitualidade e que pode, assim, ser interpretada quanto ao fato de que a metaforologia esteve à serviço e à disposição para que a história dos conceitos - antes dos projetos de léxicos - tivesse em vista outros horizontes metafóricos que não apenas um trabalho sobre manifestações e imagens na etimologia e transformações de significados dos conceitos num tipo de prova filológica-histórica de uma semântica dos termos (Kranz, 2013, p. 238). Tal modo de trabalho foi levado em consideração por Blumenberg nos seus escritos da década de 1960, que podem ser vistos como também dentro de um espectro amplo de história dos conceitos, e neste sentido foi um autor constantemente referenciado por diversos trabalhos no Arquivo e no próprio HWPh, como bem destaca Gottfried Gabriel. ${ }^{25}$

Antes mesmo da publicação do primeiro volume do HWPh, Hans Blumenberg já tinha claramente para si que a história dos conceitos também é uma disciplina auxiliar, assim como a metaforologia (Blumenberg, 1970, p. 7). "A história conceitual é, para Blumenberg e Rothacker, uma ciência auxiliar histórico-filosófica; é útil e servil [dienstbar] na captura de formações históricas e suas mudanças, e pertence

25 Cf. Gabriel, 2009, p. 65-84, um dos organizadores do dicionário juntamente com Joachim Ritter, que tem uma visão muito mais conciliadora entre a metaforologia e a história dos conceitos. 
à hermenêutica das 'visões de mundo' [Weltbildern]” (Kranz, 2013, p. 243). Deste modo, um dicionário para a história dos conceitos seria a realização e conclusão deste "serviçalismo". Com a publicação do primeiro volume do HWPh essa tensão ainda ficou mais clara, apesar de que sempre cortês e com críticas sutis (Blumenberg, 1971, p.161-165). Esta foi apenas a consumação de uma separação anunciada pelo tipo de compreensão histórica que constitui o modo de tratamento dos problemas filosóficos para Blumenberg.

Podemos concluir este item dizendo que a metaforologia sofre de um efeito metonímico, pois se já não podemos nos referir a ela apenas pelos termos dos Paradigmas de 1960, precisamos nos referir ao conjunto destas reflexões dentro dos marcos da teoria da não-conceitualidade. Pois esta abarca as pretensões iniciais metaforologia e tenta dar conta de outras dimensões que fogem a estrita conceitualidade, não se resumindo jamais ao metafórico strictu senso, mas à metáfora enquanto categoria filosófica portadora de outras dimensões não-conceituais ligadas diretamente ao mundo da vida, ${ }^{26}$ como é o caso do simbólico, do mítico, do cômico, ou seja, de tudo aquilo que a filosofia moderna de base cartesiana, por não achar digno de racionalidade, não deu conta de explicar e simplesmente reduziu a um mero aspecto retórico. ${ }^{27}$

\section{Conclusão}

Paradigmas para uma Metaforologia é apenas um pequeno ponto na recepção do autor, mas que ainda hoje chega a ser o texto mais conhecido devido ao apelo e à sedução da metáfora, pois ela também é um dos cantos das sereias da filosofia contemporânea. Apesar de nosso esforço em reconstruir o itinerário da metaforologia, o retorno a um possível terminus a quo serve apenas para esclarecer e desmitificar certas leituras na recepção de Hans Blumenberg. Nesta relação entre metaforologia e história dos conceitos podemos dizer que não são projetos excludentes, e talvez sequer concorrentes, tanto que os editores que sucederam Joachim Ritter na fase final do já mencionado dicionário histórico, Karlfried Gründer e Gottfried Gabriel destacam a importância que a metaforologia teve do início ao fim do dicionário em muitos verbetes e que na visão do último editor não existiria uma linha limítrofe entre

26 Blumenberg se dedicou largamente a discutir releituras sobre o Mundo da Vida [Lebenswelt] da tradição fenomenológica, e com grande razão foi um modo de rearticulação da própria metaforologia, como ele explicita em "Naufrágio com Espectador: paradigma de uma metáfora da existência" (Blumenberg, 1979, p. 77), mas que ficou ainda mais claro a partir do texto póstumo “Teoria do Mundo da Vida" (Blumenberg, 2010b, p. 137) quando, por exemplo, a metafórica do mito é vista como modo de tornar conhecido por meio do mundo da vida aquilo que era mundanamente desconhecido.

27 Como muito bem pode-se ver em "Aproximação antropológica à atualidade da Retórica" (Blumenberg, 2012a, p. 104-105) 
conceito e metáfora (Haverkamp; Mende, 2009, p. 11-12). Neste sentido nos parece lapidar a conclusão de Kurt Flash: "Embora Blumenberg coloque a metaforologia como uma 'disciplina auxiliar' sob o comando da história conceitual, estes eram desvios retóricos para afastar uma possível leitura anti-intelectualista. Ele corrigiu a história dos conceitos, ele não a serviu." (Flasch, 2017, p. 367.)

Conforme foi exposto, podemos compreender como o texto de Paradigmas nasce inserido num projeto de história dos conceitos filosóficos e, portanto, com ela dialoga. Contudo, concluir que a metaforologia ainda serve enquanto simples auxiliar para história dos conceitos seria um salto hermenêutico, especialmente no desenvolvimento do itinerário filosófico de Hans Blumenberg. Por outro lado, tratar a metaforologia como um campo acessório e dependente da história dos conceitos após Observações sobre Metáforas (Blumenberg, 1971) seria resultado de uma má hermenêutica da obra do autor ao não se perceber as distinções, pretensões e potenciais dos projetos. Há claramente uma ampliação do escopo da metaforologia através da leitura do texto "Panorama sobre uma teoria da não-conceitualidade" contido em Naufrágio com espectador de 1979, bem como os já mencionados textos da década de 80, e ainda com mais razão a partir de 2007 com a publicação dos textos póstumos contidos na Teoria da Não-Conceitualidade ${ }^{28}$ [Theorie der Unbegrifflichkeit] (Blumenberg, 2007). Como se pode perceber com o estudo minucioso de Margarita Kranz, há um significativo percurso do início ao fim da relação entre a história dos conceitos e a metaforologia, tanto em cartas, como nos próprios textos de Blumenberg. Mudança que se concretiza na década de 70 com publicações como Observações sobre as Metáforas de 1971, e também marcada no texto Aproximação Antropológica à atualidade da retórica do mesmo ano, mesmo que publicado inicialmente apenas em italiano, só republicado em obra 10 anos depois em Realidade em que vivemos (Blumenberg, 2012, p. 115-116). Neste sentido, Hans Blumenberg deixa bastante claro que Erich Rothacker, assim como ele próprio, estava a pensar na metaforologia em 1960 como um método subsidiário à história dos conceitos (Blumenberg, 1979, p. 77). Todavia, a metafórica se tornou com o tempo apenas um restrito caso de nãoconceitualidade, e também não limitada ao núcleo restrito pela busca das metáforas absolutas. Assim diz o próprio Blumenberg em Panorama sobre uma teoria da nãoconceitualidade de 1979, gestado enquanto preleções em 1975:

Poder-se-ia dizer que o ponto de vista se inverteu: [a metaforologia] já não está primariamente relacionada com a constituição da conceitualidade, senão com as conexões retrospectivas com o mundo da vida como apoio permanente - embora não esteja constantemente presente - da motivação de toda teoria (Blumenberg, 1979, p. 77).

28 Ou, no Brasil, a partir de 2013 com a tradução de Luiz Costa Lima. 
Mais importante que o terminus a quo é o terminus ad quem da metaforologia, para usar a expressão de Stoellger (2009, p. 219). Por isso, ao inserir a metaforologia no mundo da vida [Lebenswelt], Hans Blumenberg ampliou a compreensão da metáfora para além de uma mera figura de linguagem, como o catálogo dos tropos da retórica na idade moderna. Há também a superação de uma mera função auxiliar ao campo pré-conceitual, como na primeira formulação da metaforologia. Nesta reformulação estaria a metaforologia a adentrar nas profundezas da relação entre existência e linguagem, ou seja, como metaforicamente, simbolicamente e miticamente procedemos em nossa relação com o mundo e com o conceito de realidade. Pois a “metáfora articula o campo verbal da relação primária com a realidade e o campo secundário da relação com a possibilidade” (Blumenberg, 2013a, p. 145-146).

Por fim, inegavelmente, Hans Blumenberg se insere em uma linhagem de autores do século XX que questiona o papel de uma razão absoluta na construção dos discursos filosóficos e das visões de mundo. A crítica de Hans Blumenberg se aproxima também da própria crítica ao logocentrismo feita por Derrida, mas não cairia num irracionalismo como comumente atribuído aos filósofos que criticam a racionalidade. A posição de Blumenberg quanto a isso é clara: "O princípio da razão insuficiente contudo não se confunde com o postulado de renúncia à razão" (Blumenberg, 2012b, p. 295). Do mesmo modo, a insuficiência do conceito não se confunde com a renúncia ao conceito. A sua crítica deve ser realizada através de uma metaforologia ampliada por uma teoria da não-conceitualidade que está imersa no horizonte de uma antropologia fenomenológica, como pretendeu Hans Blumenberg em seus últimos escritos.

\section{Referências}

Adeodato, J. M. (1996). Filosofia do direito: Uma crítica à verdade na Ética e na Ciência. $1^{a}$ ed. São Paulo: Saraiva.

Adeodato, J. M. (2014). Uma teoria retórica da norma jurídica e do direito subjetivo. $2^{a}$ ed. São Paulo: NOESES.

Blumenberg, H. (1950). Die ontologische Distanz: Eine Untersuchung über die Krisis der Phänomenologie Husserls (Tese de Habilitação). Christian-AlbrechtUniversität zu Kiel, Philosophische Fakultät, Habilitationschrift.

Blumenberg, H. (1970). Neugierde Und Wissenstrieb: Supplemente zu “Curiositas”. Archiv für Begriffsgeschichte, 14, 7-40.

Blumenberg, H. (1971). Beobachtungen an Metaphern. Archiv für Begriffsgeschichte, 15, 161-214.

Blumenberg, H. (1979). Schiffbruch mit Zuschauer: Paradigma einer Daseinsmetapher. Frankfurt am Main: Suhrkamp Verlag.

Blumenberg, H. (1981). Die Lesbarkeit der Welt. Frankfurt am Main: Suhrkamp. 
Blumenberg, H. (1990). Naufrágio com Espectador. Tradução de Manuel Loureiro. Lisboa: Vega.

Blumenberg, H. (1997). Ein mögliches Selbstverständnis: aus dem Nachlass. Stuttgart: Reclam.

Blumenberg, H. (2001). Ästhetische und metaphorologische Schriften. Haverkamp, A. (org.). Frankfurt am Main: Suhrkamp Verlag.

Blumenberg, H. (2007). Theorie der Unbegrifflickeit. Haverkamp, A. (org.). Berlin: Suhrkamp Verlag.

Blumenberg, H. (2010a). “'Imitação da natureza': contribuição à pré-história da ideia do homem criador”. In: Lima, L. C. (org. ). Mímesis e a reflexão contemporânea. Rio de Janeiro: EdUERJ.

Blumenberg, H. (2010b). Theorie der Lebenswelt. Sommer, M. (org.). Berlin: Suhrkamp Verlag.

Blumenberg, H. (2012a) Autoconservação e inércia: Para a constituição da racionalidade moderna. Tradução de Luiz Costa Lima. Viso - Cadernos de Estética Aplicada, 6(12), 1-43.

Blumenberg, H. (2012b). Wirklichkeiten, in denen wir leben. Stuttgart: Reclam.

Blumenberg, H. (2013a). Teoria da Não Conceitualidade. Tradução de L Costa Lima. Belo Horizonte: Editora UFMG.

Blumenberg, H. (2013b). Paradigmen zu einer Metaphorologie. Haverkamp, A. (org.). Frankfurt am Main: Suhrkamp Verlag.

Blumenberg, H. (2015). Schriften zur Technik. Schmitz, A. \& Stiegler, B. (orgs.). Frankfurt am Main: Suhrkamp Verlag.

Blumenberg, H. (2018). Aproximação antropológica à atualidade da retórica. Tradução de Luiz Costa Lima. História da Historiografia, 26, 278-304. DOI: https: //doi.org/10.15848/hh.v0i26.1354

Blumenberg, H. (2019). Die nackte Wahrheit. Zill, R. (org.). Frankfurt am Main: Suhrkamp Verlag.

Blumenberg, H. (2020a). Realität und Realismus. Zambon, N. (org.). Frankfurt am Main: Suhrkamp Verlag.

Blumenberg, H. (2020b). History, Metaphors, Fables: A Hans Blumenberg Reader. Ithaka: Cornell University Press.

Feron, O. (2015). Apresentação do dossiê Hans Blumenberg. Aurora 27(41), 423-427. DOI: http://dx.doi.org/10.7213/aurora.27.041.AP01

Flasch, K. (2017). Hans Blumenberg: Philosoph in Deutschland: die Jahre 1945 bis 1966. Frankfurt am Main: Vittorio Klostermann.

Gabriel, G. (2009). Kategoriale Unterscheidungen und »absolute Metaphern«: Zur systematischen Bedeutung von Begriffsgeschichte und Metaphorologie. In: Haverkamp, A., Mende, D. (orgs.). Metaphorologie: Zur Praxis von Theorie. Frankfurt am Main: Suhrkamp.

Gadamer, H. G. (1970). Begriffsgeschichteals Philosophie. Archivfür Begriffsgeschichte, 14, 137-151. 
Gehring, P. (2014). Metapher. In: Buch, R. \& Weidner, D. (orgs.). Blumenberg lesen: Ein Glossar. Berlin: Suhrkamp Verlag.

González-Cantón, C. (2005). Blumenberg versus Heidegger: La metaforología como destino del análisis existencial. Anuario Filosófico, XXXVIII/3, 725-746. DOI: https://doi.org/10.15581/009.38.3.725-746

Hacke, J. (2006). Philosophie der Bürgerlichkeit. Die liberalkonservative Begründung der Bundesrepublik. Göttingen: Vandenhoeck \& Ruprecht.

Haverkamp, A. (1996). Theorie der Metapher. Darmstadt: Wissenschaftliche Buchgesellschaft.

Haverkamp, A. (2018). Metapher - Mythos - Halbzeug: Metaphorologie nach Blumenberg. Berlin, De Gruyter.

Haverkamp, A. \& Mende, D. (orgs.). (2009). Metaphorologie: Zur Praxis von Theorie. Frankfurt am Main: Suhrkamp.

Konersmann, R. (2012). Handbuch Kulturphilosophie. Stuttgart: J.B. Metzler.

Koselleck, R. (1967). Richtlinien für das Lexikon politisch-sozialer Begriffe der Neuzeit. Archiv für Begriffsgeschichte, 11, 81-99.

Kranz, M. (2011). Begriffsgeschichte institutionell: Die Senatskommission für Begriffsgeschichte der Deutschen Forschungsgemeinschaft (1956-1966) Darstellung und Dokumente. Archiv für Begriffsgeschichte, 53, 153-226.

Kranz, M. (2013). Blumenbergs Begriffsgeschichte: Vom Anfang und Ende aller Dienstbarkeiten. In: Borck, C. (org.). Hans Blumenberg beobachtet: Wissenschaft, Technik und Philosophie. Freiburg: Verlag Karl Alber.

Lima, L. C. (1980). Mímesis e modernidade: Formas das sombras. Rio de Janeiro: Graal.

Lima, L. C. (2015). Os eixos da linguagem: Blumenberg e a questão da metáfora. Rio de Janeiro: Iluminuras.

Müller, E.; Schmieder, F. (2016). Begriffsgeschichte und historische Semantik: Ein kritisches Kompendium. Berlin: Suhrkamp.

Oliveira, R. T. (2013). Decisão e História: Uma Exploração da Experiência Jurídica a partir das Estruturas Basais Da Decisão Judicial (Tese de Doutorado). PósGraduação em Direito da UNISINOS, São Leopoldo, RS.

Ritter, J. (1967). Leitgedanken und Grundsätze des Historischen Wörterbuchs der Philosophie. Archiv für Begriffsgeschichte, 11, 75-80.

Ritter, J., Gründer, K., Gabriel, G. (orgs.). (2007). Historisches wörterbuch der philosophie. Bd. 1-13. Basel: Schwabe.

Rüter, C. (2020). Hans Blumenberg: Der unsichtbare Philosoph. 375 Media. 102 min.

Santos, H. L. R. (2020). Metaforologia e Teoria Da Não Conceitualidade Aplicadas À História Do Direito Penal: 0 Hiato De Racionalidade No Discurso Criminal. Revista da faculdade de direito da UFMG, 76, 299-319. DOI: http://doi.org/10.12818/P.0304-2340.2020V76P299 
Stoellger, P. (2000). Metapher und Lebenswelt: Hans Blumenbergs Metaphorologie als Lebenswelthermeneutik und ihr religionsphänomenologischer Horizont. Tübingen: Mohr Siebeck.

Stoellger, P. (2009). Über die Grenzen der Metaphorologie: Zur Kritik der Metaphorologie Hans Blumenbergs und den Perspektiven ihrer Fortschreibung. Haverkamp, A. \& Mende, D. (orgs.). Metaphorologie: Zur Praxis von Theorie. Frankfurt am Main: Suhrkamp. 